\title{
Association for European Paediatric and Congenital Cardiology (AEPC)
}

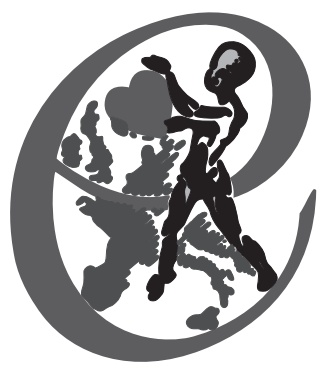

A EPC WAS FOUNDED IN LYON IN 1963 (as Association Européenne pour la Cardiologie Pédiatrique) and subsequently has created a network of specialists who are committed to the practice and advancement of Congenital Cardiology and closely related fields. Cardiology in the Young is the official journal of the AEPC. AEPC offers a free subscription of 'Cardiology in the Young' (CitY) as part of the annual membership fee. The membership also offers several other benefits.

The overall membership of the Association currently stands at 1300 paediatric cardiologists and other specialists working in the field of paediatric cardiology and its related disciplines. As far as we are aware, the AEPC is the largest democratically administered global association in the field of paediatric and congenital cardiology. Members of the AEPC originate from virtually all countries in Europe and it is encouraging that there are now increasing numbers of members from all the continents. New members are very welcome as they bring with them new ideas and innovations.

AEPC and its Working Groups aim to enhance collaboration amongst members for scientific research, promoting training, professional development and to maintain high standards of professional practice. The work on behalf of children and patients with congenital heart diseases is global and the AEPC has made itself a global organisation by its close collaboration with other international organizations. These include the European Society of Cardiology; the Japanese Society of Paediatric Cardiology and Cardiac Surgery (JSPCCS); the European Association for Cardio-Thoracic Surgery (EACTS) and; the Adult Congenital and Pediatric Cardiology Section of the American College of Cardiology (ACC); the Asia Pacific Pediatric Cardiac Society (APPCS); the European Heart Surgeons Association (ECHSA), the World Congress of Paediatric Cardiology and Cardiac Surgery and several others.

\section{Working groups}

Several activities of AEPC are organized by the Working Groups. The Working Groups represent different subspecialties and specific areas of paediatric and congenital cardiology. The Association now has 13 Working Groups, to bring together workers with similar interests in order to facilitate research and collaboration and to organise teaching and training.

\section{Annual meetings}

An Annual Meeting and an Update-On Course are organised by the AEPC, usually in the third week of May in collaboration with one of the member countries. The AEPC organizes 2-3 Teaching courses for trainees in Paediatric Cardiology each year. Additional symposia and courses are usually a part of the annual meetings. 


\section{The International Society for Nomenclature of Paediatric and Congenital Heart Disease}

$\mathrm{T}$ He International Society for Nomenclature of Paediatric and Congenital Heart Disease (ISNPCHD) is an established not-for-profit organization, incorporated in Canada, with the collective mission to identify, standardize, and maintain an international system of nomenclature, the International Paediatric and Congenital Cardiac Code (IPCCC), to enhance global communication and facilitate patient care, research, and training in paediatric and congenital heart care across disciplines. In other words, the IPCCC provides a common language and terminology, inclusive of definitions and imaging, which covers the entire field of diagnostic and procedural terms for paediatric and congenital heart care. The IPCCC is the product of the cross-mapping work by the ISNPCHD Nomenclature Working Group during the decade following the publication in 2000 of two similar and complementary nomenclature systems, namely the International Congenital Heart Surgery Nomenclature and Database Project under the auspices of the European Association for Cardio-Thoracic Surgery and Society of Thoracic Surgeons, and the European Paediatric Cardiac Code under the auspices of the Association for European Paediatric Cardiology. The IPCCC is owned by the ISNPCHD but is digitally published for free download for private use (www.ipccc. net) in these two Societal versions, both with a Long List of over 10,000 terms with qualifiers, and a Short List of up to 1000 terms for use in databases when comparing institutional outcomes, both nationally and internationally. The Long Lists of the IPCCC comprehensively cover the field of paediatric and congenital cardiac care, including diagnoses of congenital and related acquired pathology, comorbid conditions, transcatheter and operative procedures, and a full list of postprocedural complications. The Short Lists are used within databases across the world with over 500,000 registered patients. The ISNPCHD encourages the commercial use of the
IPCCC by requiring and providing free-of-charge license agreements for its use, to ensure that the IPCCC remains unaltered by parties other than the ISNPCHD.

Since 2007 the ISNPCHD has been operating through three working groups:

- The Nomenclature Working Group, which continues to maintain, develop, expand, update, and preserve the IPCCC;

- The Definitions Working Group, which is engaged in writing definitions for the terms in the IPCCC. More recently this initiative has focused on the terms provided by the ISNPCHD at the behest of the World Health Organization (WHO) for the $11^{\text {th }}$ revision of the International Classification of Diseases;

- The Archiving Working Group, which is engaged in linking images and videos to the IPCCC, including cardiac morphologic specimens, echocardiography, angiography, computerized axial tomography, magnetic resonance imaging, intraoperative photographs and intraoperative videos.

The ISNPCHD, through the IPCCC, enables institutions from around the world to seamlessly communicate with each other, comparing and then improving outcomes and the quality of care that is given to children, young people, and adults born with malformed hearts. This common language enables institutions to learn from those hospitals performing best at a global level, as well as facilitating research projects, such as comparing the longer term quality of life and complications in those who have required operative and transcatheter interventions. In addition, the nomenclature with corresponding definitions and matching imaging, enhances teaching of this specialty to the next generation of clinicians dedicated to pediatric and congenital cardiac care, both in the developed and developing world. 
Volume $27 \bullet$ Supplement 5 • Pages S3-S15
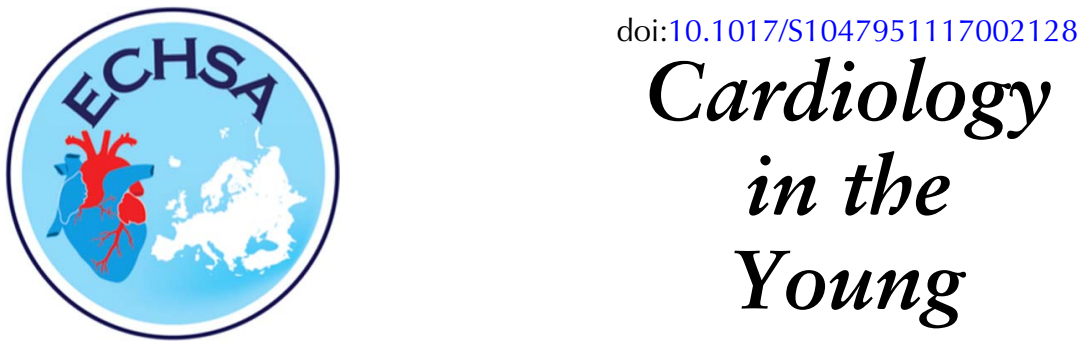

(C) 2017 Cambridge University Press

\section{Abstracts of the Annual Spring Meeting 2017 of the European Congenital Heart Surgeons Association, Leicester, UK, 19-20th May, 2017}

\section{CR01}

The $[\mathbf{I}, \mathrm{L}, \mathrm{L}]$ story

Nosáll M., Valentík P., Sagát M., Kántorová A., Nagi A.S. Department of Cardiac Surgery, Children's Heart Centre Slovakia, Bratislava, Slovakia

Background: The Nikaidoh procedure is supposed to work for most complex TGA/VSD/PS or DORV/VSD/PS anatomy including inlet VSD. We present a "worst case" video of a patient with situs inversus [I,L,L], L-TGA/PS and inlet VSD.

Case report summary: At the age of 10 months, the patient underwent an MBT shunt takedown and a modified Nikaidoh operation with a direct anastomosis of RV to PA. Due to failing heart ECMO was started right after the operation. An additional muscular inlet VSD was closed by following reoperation. Echocardiography revealed persistent shunting in newly diagnosed multiple apical VSD's. Two catheterisations failed to completely eliminate the shunting by repeated insertion of occluders into the apical defects. Three subsequent attempts of weaning from ECMO failed. After 20 days on ECMO a BiVad Berlin Heart support was implanted along with occlusion of the RVOT. Renal failure occurred, necessitating peritoneal dialysis. Eight days later, the patient underwent a heart transplant into the situs inversus anatomy. The postoperative course was complicated by ongoing renal failure, sepsis and repeated bleeding from the airways. Despite a good graft function the organ function didn't recover and the patient eventually died on the 47-th postoperative day during another episode of massive airway bleeding. The autopsy of the patient's heart showed multiple defects at the apical level.

Multiple VSD's associated with a large inlet defect pose a diagnostic and therapeutic challenge. In association with situs inversus and a complex transposition anatomy, it might be more reasonable to choose a single ventricle surgical strategy.

\section{CR02}

Left AV valve regurgitation after AVSD repair: an out-ofthe-box surgical approach

Silva M.(1), Cerejo R.(1), Rodrigues R.(1), Trigo C.(2), Fragata I.(3), Pinto F.(2), Fragata J.(1)

Cardiothoracic Surgery Department(1), Pediatric Cardiology

Department(2) and Anesthesiology Department(3), Hospital De Santa

Marta - CHLC, EPE, Lisboa, Portugal

Background: Atrioventricular septal defect (AVSD) is a congenital heart malformation characterised by a broad spectrum of lesions, which management strategy depends on its presentation and severity.

Case report: A nine-month-old male, evacuated from Cape Verde with the diagnosis of complete AVSD Rastelli's type A, associated with an ostium primum atrial septal defect (ASD), small ventricular septal defect (VSD) and left superior vena cava (LSVC). Surgical repair was performed with closure of the left atrioventricular (AV) valve's cleft, ASD closure using autologous pericardial patch, VSD direct closure and LSVC ligation. Although initial postoperative period was free from complications, one week later clinical deterioration occurred with signs of heart failure and echocardiographic documentation of severe left AV valve stenosis/ regurgitation, and evidence of secondary pulmonary hypertension (PHT), therefore an AV valve plasty was performed in order to repair the dehiscence cleft closure. After one month, recurrence of cleft closure dehiscence imposed a transseptal approach was used for AV valvuloplasty with cleft reclosure and bovine pericardial patch for ASD closure. The postoperative period was complicated by bilateral pleural effusion, right pneumothorax, urinary tract infection (Proteus mirabilis) and subdural hematoma. After medical therapy optimization and clinical improvement, the infant was discharged. Following four months of clinical stability, he was readmitted for decompensated heart failure, with evidence of severe left AV valve restenosis/regurgitation and secondary PHT. As third reoperation, a mechanical valve prosthesis $21 \mathrm{~mm}$ within a Dacron graft $22 \mathrm{~mm}$ was implanted in mitral position using the cylinder technique. Progressive clinical recovery was achieved with no further complications. At six-months follow-up, the infant remained asymptomatic, with mild delayed psychomotor development and normal functioning prosthesis.

Recurrent AV valve regurgitation in the context of AVSD is rare, but can be challenging. We present a reproducible and safe technique to deal with it.

\section{CR03}

Critical aortic valve stenosis with borderline left ventricle Muganthan T.(1), Skinner G.(1), Shebani S.(1), Mimic B.(1), Cvetkovic M.(1), Mehta C.(2), Barron D.(2), Corno A. F.(1) East Midlands Congenital Heart Centre, University Hospitals Leicester, Leicester, UK(1), Birmingham Children Hospital, Birmingham, UK(2)

Background: Staged biventricular repair can be preferable to univentricular approach with Norwood operation in critical aortic valve stenosis (AoVSt) with borderline left ventricle (LV), because 
of better long-term outcomes. The decision-making process must consider multiple variables, potentially changing over time. Case Summary: A 6-day-old neonate, $3.5 \mathrm{~kg}$, was admitted in cardiogenic shock. Echocardiography showed critical AoVSt with impaired left ventricular (LV) function and maintained antegrade flow, suprasystemic right ventricular (RV) pressure, atrial septal defect (ASD) and persistent ductus arteriousus (PDA), both with bidirectional flow, and hypoplastic aortic arch. Mitral Valve (MV) and AoV size were respectively $8.8 \mathrm{~mm}(\mathrm{z}=-1.76)$, and $6.0 \mathrm{~mm}(\mathrm{z}=-0.99)$, and indexed 3DRT LV volume $19 \mathrm{~mL} / \mathrm{m}^{2}$, discriminant score (DS) $=0.56$ with mild Endocardial Fibro-Elastosis. After stabilization, aortic valvotomy with bilateral pulmonary artery banding (PAB) was performed at 16 days of age, leaving the PDA open. The patient was gradually weaned from inotropic and respiratory support, and remained stable on PGE for 11 weeks. At 3 months of age, $4.6 \mathrm{~kg}$, echocardiography showed improving LV function, MV and AoV size were respectively $12 \mathrm{~mm}(\mathrm{z}=-0.83)$, and $6.3 \mathrm{~mm}(\mathrm{z}=-2.29)$, and indexed 3DRT LV volume $21 \mathrm{~mL} / \mathrm{m}^{2}$, discriminant score (DS) $=0.53$. A Ross-Konno procedure plus aortic arch repair, ASD closure and bilateral PA debanding, was performed using a $14 \mathrm{~mm}$ homograft for the RV outflow tract. Post-operative recovery was uneventful, using only Milrinone for inotropic support. Echocardiography confirmed good ventricular function, without $\mathrm{LV}$ outflow obstruction or aortic valve regurgitation, and RV pressure half systemic.

Respiratory weaning was slow due to increased LA pressure when stressed, with extubation on day 7.

Discussion: The surgical approach of neonatal aortic valvotomy with bilateral PAB, keeping the PDA open, allows maintaining the options available for biventricular repair, especially when LV function is impaired at presentation. The Ross-Konno procedure, despite reported high early mortality, provides encouraging longterm outcomes, preferable to univentricular pathways.

\section{CR04}

Venoarterial extra corporeal membrane oxygenation in a severe and refractory case of junctional ectopic tachycardia Rito T.(1), Trigo C.(1), Rodrigues R.(2), Fragata J.(2), Pinto F.(1) Pediatric Cardiology Department(1) and Cardiothoracic Surgery Department (2), Hospital De Santa Marta - CHLC, EPE, Lisboa, Portugal

Background: Junctional ectopic tachycardia (JET) is an automatic arrhythmia with a high mortality rate, which complicates the postoperative courses in up to $10 \%$ of congenital heart surgery cases. In this setting, ventricular filling is decreased due to atrioventricular dessincrony and shortened diastolic filling, consequently lowering cardiac output. Simultaneously, myocardial effort and oxygen demand increases, while less oxygen is available. Altogether, this can result in potentially fatal Low Cardiac Output Syndrome (LCOS). The self-limited nature of JET makes ECMO support an important addition to conventional therapy in most severe cases, allowing circulatory assistance, until spontaneous conversion of the arrhythmia occurs.

Case Report: We report a case of tetralogy of Fallot in a 6-monthold infant, with no previous rhythm disturbance, submitted to surgical repair, consisting of right ventricular outflow tract enlargement and ventricular septal defect repair, with 83 minutes of cardiopulmonary bypass time. He was transferred to ICU on dopamine and dobutamine perfusion, respectively at 3 and $1 \mathrm{mcg} /$ $\mathrm{Kg} / \mathrm{min}$. Immediately after bypass, periods of normal sinus rhythm alternated with junctional rhythm, which accelerated to JET with heart rate of $230 \mathrm{bpm}$. This warranted aggressive attempts on rhythm and rate control: intravenous Amiodarone perfusion, inotropes minimization, analgesia and sedation intensification, $\mathrm{pH}$ and serum electrolytes normalization, volume administration and active cooling. Even though rhythm was not controlled, junctional rate was temporary slowed, allowing atrioventricular synchrony through atrial pacing. Nonetheless, during the following hours, JET perpetuation led to severe and refractory heart failure with LCOS and anuric renal failure. The patient was therefore supported on ECMO and peritoneal dialysis. After 52 uneventful hours of ECMO, normal sinus rhythm was restored, which led to hemodynamic improvement, allowing ECMO suspension after 78 hours. This case highlights the severity of JET, the importance of prompt recognition and treatment and ECMO role in refractory cases with circulatory failure.

\section{CR05}

When a Perfect Fontan circuit has a progressive clinical worsening: challenges in management

Cerejo R.(1), Silva M.(1), Rodrigues R.(1), Trigo C.(2), Fragata I.(3), Pinto F.(2), Fragata J.(1)

Cardiothoracic Surgery Department(1), Pediatric Cardiology Department (2) and Anesthesiology Department(3), Hospital De Santa Marta CHLC, EPE, Lisboa, Portugal

Background: Fontan operation has immediate good results, but late complications can represent an important challenge. Numerous treatment strategies have been used, including medical, interventional and surgical therapies. In some cases, heart transplantation is the only option to improve survival and clinical status. Factors contributing to Fontan failure remain poorly defined.

Case Report: An 18-year-old female, born with double-inlet left ventricle, transposition of the great arteries, and aorta coarctation was submitted to coarctation repair and pulmonary artery banding in the neonatal period, and, eight months later, to a Damus-Kaye-Stansel anastomosis and bidirectional cavopulmonary anastomosis. At 3 years, the Fontan circulation was completed by a fenestrated extracardiac conduit. As complication, she had a third-degree atrioventricular block, treated by double-chamber epicardial pacing. Twelve years later severe Protein Losing Enteropathy (PLE) was diagnosed. Fontan pathway mean pressure was $15 \mathrm{mmHg}$ at cardiac catheterization, with sluggish flow in the inferior vena cava (fenestration was not patent). She had no systemic outflow tract obstruction or atrio-ventricular valve regurgitation. Aggressive medical therapy did not improve her clinical status. She was included in transplantation list, and while waiting, was submitted to surgery of decompression of the thoracic duct (15-year-old). Despite complete occlusion of the innominate-atrial anastomosis, her clinical status improved in the next two years and she was withdrawn from transplant list. At 17 years her clinical status worsened, with severe PLE; echocardiogram and catheterization showed Fontan circuit without elevated pulmonary pressions or cardiac residual lesions. She had heart transplantation six months later, without technical complications, but never fully recovered. Four months later, still admitted in our department, she died with multi-organic failure.

Conclusion: A growing number of so called "perfect Fontans" fail without anatomic or functional explanation. While the reasons for failure are far from clear, it seems advisable to refer these patients for transplant as early as possible.

\section{OP01 \\ Single-centre experience of incorporating knowledge- based reconstruction for right and left ventricular volumetric data into clinical practice Shebani S. O., Skinner G.}

East Midlands Congenital Heart Centre. Glenfield Hospital. Leicester. UK

Background: Knowledge-based reconstruction (KBR) is a new technique for calculating the volume of cardiac chambers 
accurately. The technique can be applied to 3D datasets (e.g. MRI scans), but can also be used with conventional 2D echocardiography by tracking the probe position and orientation in 3D space. It is particularly useful for assessing the volume of the right ventricle without having to undergo an MRI scan.

Methods: We acquired a KBR system in March 2015, and have been putting it into practice. We have performed 72 studies in 43 patients over an 18-month period, ages 2-70 years (mean 16.3 years median 12years), 35 patients (81.4\%) were between $2-12$ years 16 studies were left ventricle, 56 studies were on the right ventricle, 4 excluded for inability to analyze due to either unstable ECG or very poor windows. Of the remaining 52 studies, an additional 7 were reanalyzed due to inter-observational variation by $>15 \%$ for.

Indications were mainly for post surgical Tetralogy of Fallot variants or post pulmonary valve dilation resulting in free pulmonary regurgitation or mixed valve disease with resulting significant right ventricular volume loading. In a subset, we have performed analysis on 13 patients who underwent pulmonary valve replacement, giving pre- and post- surgical RV volume and function analysis, all 13 patients had Cardiac MRI pre-surgery, that was comparable to the pre-surgical KBR analysis.

Bland Altman analysis was performed to assess inter-observational agreement.

Results: Pearson correlation coefficient of $-0.108(95 \% \mathrm{CI}=-$ $0.370-+0.169)$ the mean bias is $2.06 \%$ with a $95 \%$ limit of agreement of $(-12.3 \%-16.4 \%)$ this correlates very well with the original studies in the field.

Conclusion:

I. KBR of RV and LV can be preformed with good reliability and good alternative to MRI, However To adapt this technique in any centre:

II. Recommendations:

1. at least 12 months for the experience to develop in any centre and the inter-observational variability to minimize to keep up with those of the Gold standard MRI and the already established data on KBR in the literature

2. Clearly agreed protocol of dot number and placement and cycle identification

3. Useful for serial measurements.

\section{OP02 \\ Clinical results of the "double barrel" Damus-Kaye-Stansel operation for patients with subaortic obstruction in univentricular heart \\ Kornoukhov O., Ilyin $V$. \\ Cardiac Surgery Department, Filatov Children's Hospital, Moscow, Russian Federation}

Background: We have reviewed our experience with the "double barrel" Damus-Kaye-Stansel operation (dbDKS) in patiens with univentricular hearts following pulmonary artery banding (PAB). The main purpose was to investigate the dbDKS efficiency in terms of relieving a subaortic obstruction without complications. Methods: From January 2010 to December 2016, 9 patients with functionally single ventricle and ventriculo-arterial discordance underwent $\mathrm{PAB}$ (median 28 days, range $3-55$ days; $3.4 \mathrm{~kg}$ ). Aortic coarctation was simultaneously repaired in 4 cases (44\%). All 9 patients subsequently underwent PA debanding, creation of DKS connection at a median age of 15.1 months (4.5-40.8 months) and mean weight $9.0 \pm 2.43 \mathrm{~kg}$ and also underwent bidirectional Glenn procedure. Catheterisation angiography was performed prior to DKS. The relationship of the great arteries was anterior-posterior in all cases. The diameter of bulboventricular foramen measured in the end-systole was $9 \mathrm{~mm}$ (5-17 mm), compared to the aortic valve diameter of $14 \mathrm{~mm}(10-19 \mathrm{~mm}$, Z-score $4.27 \pm 1.62)$. One patient $(11,1 \%)$ had severe subaortic obstruction $(3.5 \mathrm{~mm})$. The median follow-up after the dbDKS was 4.3 years (0.3-6.8 years). Routine follow-up included echocardiography at 6-monthly intervals. Angiography was repeated prior to Fontan completion.

Results: There were no hospital deaths and no complications related to the dbDKS connection. The median peak systolic single ventricle to aorta gradient was reduced from 22 (10-32) $\mathrm{mm} \mathrm{Hg}$ to 6 (4-9) $\mathrm{mmHg}$ after dbDKS $(\mathrm{p}<0.001)$. Aortic and pulmonary insufficiency was trivial in all patients. Five of 9 patients $(55,6 \%)$ underwent successful Fontan completion at a median age 3.9 years (2.8-5.4 years) with no early and late deaths. Four patients are currently awaiting this completion.

Conclusions: The "double barrel" Damus-Kaye-Stansel operation is an effective and safe method of relieving subaortic obstruction in univentricular hearts and can be performed with excellent midterm results.

\section{OP03}

In-hospital interstage can decrease mortality after Norwood stage-one operation: the Brompton's experience Michielon G., Ghez O., Fraisse A., Carvalho J., Rowlinson G., Rigby M., Slavik Z., Krupickova S., Desai A., Furk A. Burmester M., Macrae D.

Royal Brompton Hospital, London, UK

Objective: Interstage mortality after Norwood stage-one remains between $12-20 \%$ in current series. We present our preliminary experience with in-hospital interstage program, aimed at facilitating escalation of care, possibly improving survival until stage-two.

Methods: A prospective study was designed for patients with diagnosis of HLHS and HLHS-variants, offering in-hospital stay after Norwood operation until stage-two completion. Daily and weekly investigational plans were tailored to the individual patient. Primary end-point was overall survival until stage-two.

Results: Between May 2015 and August 2016, 16 consecutive patients with prenatal diagnosis of HLHS (10) or HLHS-variants (6), underwent Norwood stage-one (14) or comprehensiveNorwood operation (2). Preliminary bilateral pulmonary artery banding was performed in 7. Stage-one Norwood-Sano was preferred in $12(76 \%)$, classic Norwood in $2(12 \%)$ and hybrid followed by comprehensive Norwood in 2 (12\%). In-hospital interstage was achieved in 15 patients $(93.8 \%)$. Norwood operative and interstage survival were $93.8 \%$ and $100 \%$ at 20 months (mean follow-up 11.6 \pm 2.1 months). During in-hospital interstage, 5 patients $(31.3 \%)$ required urgent and efficacious escalation of care, due to haemodynamically compromising atrial arrhythmias affecting tricuspid valve function (2), or Sano shunt stenosis (3). These potentially fatal events occurred 2.4 months after primary Norwood-Sano.

Additional interstage interventions included: residual aortic arch obstruction repair (1) neo-aortic valve repair (1), redo Sano (1), Sano-conduit dilatation (1) or stenting (1) by catheter intervention. Bidirectional Glenn (10) or comprehensive-Norwood stage2 (2) were successfully completed in 12 patients at 5.1 months with $100 \%$ survival. Two patients are currently awaiting stage-two within the in-hospital interstage plan.

Conclusions: In-hospital interstage program facilitates escalation of care, which is possibly efficacious in reducing interstage mortality after Norwood stage-one. 


\section{OP04}

Is decellularized porcine small intestine sub-mucosa (CorMatrix) patch suitable for aortic arch repair?

Smith P., Bezuska L., Kudumula V., Mimic B., Speggiorin S., Corno A. F.

East Midlands Congenital Heart Centre, Glenfield Hospital, University Hospitals of Leicester, Leicester, U.K.

Background: Decellularized porcine small intestine sub-mucosa (CorMatrix Cardiovascular, Inc, Atlanta, GA, USA) patch has been introduced for surgery of congenital heart defects, with implantation in systemic and pulmonary circulations. Because of recent reports of less than favourable long-term outcomes, we reviewed our experience with CorMatrix patch implantation. Methods: Between October 2011 and April 2016, 191 patients, median age 8 months (IQR 1.8-29.8 months, range 2 days to 42 years), received a CorMatrix patch for surgical treatment of congenital heart defects. Among them, 51 patients $(51 / 191=26.7 \%)$, median age 1.1 months (IQR 0.4-7.5 months) and median weight $4 \mathrm{~kg}$ (IQR 3-7.2 kg), where CorMatrix was used for aortic arch reconstruction $(45 / 51=88.2 \%)$ and/or aortic coarctation repair $(6 / 51=11.7 \%)$, were included in this study. All medical records were reviewed, with primary endpoints being either interventional procedure (balloon dilatation) or surgery (CorMatrix patch replacement) due to patch related complications.

Results: In a median follow-up time of $1.5 \pm 1.1$ years (range 0.6 to 2.3 years) in $10 / 51(19.6 \%)$ patients, interventional procedure $(6 / 51=11.7 \%)$ or surgery $(5 / 51=9.8 \%)$ was required because of median max velocity flow through the aortic arch/isthmus of $4.0 \pm 0.51 \mathrm{~m} / \mathrm{sec}$. The mean interval between CorMatrix implantation and interventional procedure or surgery was $174 \pm 141$ days. Two patients are scheduled for surgery soon, and two other required surgery after failed interventional procedure. No early and late mortality occurred for CorMatrix implantation and subsequent interventional procedure or surgery. Median max velocity flow through the aortic arch/isthmus for the patients who did not require interventional procedure or surgery was $1.7 \pm 0.57 \mathrm{~m} / \mathrm{sec}$.

Conclusions: CorMatrix patch for aortic arch reconstruction and/or aortic coarctation repair should be used with caution, because of a not negligible incidence of required re-interventions. Longer follow-up and comparisons with other materials should support these preliminary results.

\section{OP05}

Subclavian flap aortoplasty in neonates under $3 \mathrm{~kg}$ : adequate treatment for transverse arch hypoplasia? Suarez-Pierre A.(1), Hibino N.(1), Crawford T.C.(1), Fraser C.D. III (1), Magruder T.J.(1), Ong C.S.(1), Parsons M.(2), Ravekes W.J.(2), Jacobs M.L.(1), Cameron D.E.(1), Vricella L.A.(1)

Division of Cardiac Surgery(1) and Pediatric Cardiology(2), The Johns Hopkins University, Baltimore, MD, USA

Purpose: Subclavian flap aortoplasty (SFA) is an attractive operation for aortic coarctation in small or premature newborns by allowing to avoid end-to-end anastomosis in diminutive arteries, but its late impact on arch hypoplasia is still unknown.

Methods: This is a single-center, retrospective study of all patients $<3 \mathrm{~kg}$ undergoing SFA between 2001 and 2016. Primary outcomes included mortality and rate of re-intervention (defined as either a second surgical intervention or percutaneous balloon dilation).

Results: 30 patients underwent SFA at a mean age of 8.8 days. Mean weight was $2.45 \mathrm{~kg}$. One late death occurred in a patient with no residual gradient. Preoperative median transverse arch Z score was -2.6 (IQR: -3.01 to-1.8). At a median follow-up of 5.9 years (1.9 to 10.9$)$, median transverse arch $\mathrm{Z}$ score was -1.3 $(-1.7$ to -0.4$)$ and mean systolic arch gradient was $6.2 \pm 8.1 \mathrm{~mm}$ $\mathrm{Hg}$ (IQR: 0-27). Four patients underwent balloon aortoplasty at a median of 131 days (IQR: 96-196); one of which later required surgical re-intervention. Freedom from type of surgical reintervention was $85.4 \%$ at both 1 and 5 years.

Conclusions: SFA is a safe and effective operation for small infants with coarctation and arch hypoplasia. Re-intervention rates are low and significant arch growth can be achieved.

\section{OP06 \\ Cylinder prosthesis for atrioventricular valve replacement in pediatric and congenital heart disease Mykychak Y.(1), Borodinova O.(2), Fedevych O.(1), Yemets I.(1) Department of Cardiac Surgery(1), Department of Cardiology (2), Ukrainian Children's Cardiac Center, Kyiv, Ukraine}

Background/Purpose: There is no universal prosthesis for atrioventricular valve replacement in children, especially infants. Small annulus sizes, body growth and complex morphological conditions limit the use of mechanical valves. In 2014, we adopted cylinder replacement both for mitral and tricuspid valve replacement and now describe our short-term results.

Methods: We considered cylinder replacement for small diameter valves or infectious endocarditis. We used hand-made cylinder constructs, tailored to the annulus diameter and implanted with the running suture to the annulus and diametral stitches to papillary muscles. Prosthesis was made of decellularized equine pericardium in 15 procedures and autologous pericardium in one. Intraoperative transesophageal echocardiography was used routinely. Transthoracic echocardiography and magnetic resonance imaging were used for follow-up.

Results: Between October 2014 and February 2017, 16 (6 mitral and 10 tricuspid) atrioventricular cylinder valve replacements were performed in 13 patients. Five patients had Ebstein's anomaly, one - TV dysplasia, two - infective endocarditis of TV, two severe MV stenosis and three - severe mitral insufficiency. All valves were competent and unobstructed immediately after implantation. Follow-up was complete for all patients (1 to 22 months). There were two operative and two late deaths. Two patients were re-operated during the same admission due to papillary stitches tear. Later, three patients received new cylinder valve replacement and one patient - mechanical valve. Two patients after MV replacement and one after TV replacement have moderate to severe prosthesis stenosis.

Conclusions: Cylinder valve replacement is a feasible option for infants and children with complex atrioventricular valve disease. Further development of this technique could provide a versatile and simple method. The best material for cylinder valve prosthesis is yet to be found.

\section{OP07 \\ Late pulmonary valve replacement after complete repair of Tetralogy Fallot (TOF): A 20-year experience Zografos P.M.(1,2), Protopapas E.M.(1,2), Hakim N.I.(1,2), Zavaropoulos P.(1,2), Alexopoulos C.(3), Sarris G. $(1,2)$ Athens Heart Surgery Institute, Athens, Greece(1), Department of Congenital Cardiac Surgery (2) and Pediatric Cardiac Intensive Care Unit(3), Iaso Children's Hospital, Athens, Greece}

Background: Pulmonary valve insufficiency (to various degrees) after TOF repair is unavoidable for most patients, but can be well tolerated for several years. Eventually, however, pulmonary valve 
replacement (PVR) becomes indicated in an increasing proportion of patients, in order to prevent the adverse consequences of progressive pulmonary valve insufficiency. This report summarizes our experience with PVR late after compete repair of TOF.

Methods: Between 1/9/1997 and 1/2/2017, 59 patients (44 male 15 female), median age 12 years (range 5 - 46) underwent PVR late after complete TOF repair. Median time interval between repair and PVR was 10.5 (range 1-43) years. Most patients $(n=36)$ had undergone total TOF repair at other institutions, while twenty-three were among the more than 300 TOF repairs performed by our group over the same time period. Indications for PVR included symptoms, increase in right ventricle (RV) end-diastolic-volumeindex (RVEDVI) to $160 \mathrm{ml} / \mathrm{m}^{2}$ or more, and/or reduction of RV ejection fraction (RVEF) below $50 \%$, as measured by MRI. Heterologous valved conduits (Contegra ${ }^{\mathrm{R}}$, diameter 18-22mm), were used in 19 patients, 2 patients received Hancock ${ }^{\mathrm{R}}$ conduits (16 and $22 \mathrm{~mm}$ ), and all 38 remaining patients had bioprosthetic valves (Edwards-Magna $^{\mathrm{R}}, 19-29 \mathrm{~mm}$ ). Concomitant residual lesions (Tricuspid or aortic valve insufficiency, residual VSD, RVOTO or pulmonary artery stenosis) were repaired in 23 patients.

Results: There was no early or late mortality. All symptomatic patients improved their NYHA functional class to I-II. At follow up (median 8 years, range 1 to 20) RVEDVI improved from $165 \mathrm{ml} / \mathrm{m}^{2} \pm 15$ to $132 \mathrm{ml} / \mathrm{m}^{2} \pm 16(\mathrm{p}=0.003)$, and $\mathrm{RVEF}$ from $42 \% \pm 7$ to $49 \% \pm 7 \quad(\mathrm{p}=0.007)$. No patient has required redo PVR.

Conclusions: Late PVR after prior compete TOF repair can be performed safely, and results in improved patient functional status, reduced RV size and improved RV function.

\section{OP08 \\ Does normothermic high-flow cardiopulmonary bypass reduce post-operative bleeding and transfusion requirements in the pediatric population? \\ Bostock C., Chiles S. D., Speggiorin S., Cvetkovic M., Corno A. F. East Midlands Congenital Heart Centre, University Hospitals of Leicester, Leicester, U.K.}

Background: Normothermic $\left(>35^{\circ} \mathrm{C}\right)$ high-flow $(3.0-3.5 \mathrm{~L} / \mathrm{min} /$ $\mathrm{m}^{2}$ B.S.A.) cardiopulmonary bypass (CPB) in pediatric patients has been proved to provide smooth recovery, short pediatric intensive care unit (PICU) stay, reduced inotropic and respiratory support. The reduced requirement for allogenic blood transfusions and reduced post-operative chest drain losses has been reported in adult patients undergoing normothermic CPB. We studied transfusion requirements and post-operative chest drain losses in normothermic high-flow versus hypothermic CPB in pediatric patients.

Methods: Retrospective review was conducted in 127 pediatric patients undergoing cardiac surgery with normothermic high-flow $(n=62)$ or hypothermic $(n=65)$ CPB in a one-year period. Patients aged from 1 day to 16 years (median age 7.2 months) were identified from surgical records using inclusion/exclusion criteria. Blood loss and transfusion requirements in operating room and during the first 24 hours in PICU were compared between the two groups.

Results: The two groups were homogeneous (no statistical difference) regarding demographic variables, diagnosis (including ventricular septal defect, tetralogy of Fallot, complete atrio-ventricular septal defect, transposition of great arteries, total anomalous pulmonary venous connection, and re-do procedures) and type of surgical repair. Intra-operative transfusion requirements for red blood cells (RBC) and blood products were significantly less during normothermic high-flow CPB $(p=0.003)$. Transfusion requirements in PICU during the first 24 hours post-operative demonstrated significant reduction of cryoprecipitate and platelets transfusions after normothermic high-flow versus hypothermic CPB (respectively $\mathrm{p}=0.021$ and $\mathrm{p}=0.025$ ), but no significant difference was found in transfusions of RBC and fresh frozen plasma. Chest drain losses on arrival to PICU and at 4 hours were significantly lower after normothermic high-flow versus hypothermic $\mathrm{CPB}$ (respectively $\mathrm{p}=0.04$ and $\mathrm{p}=0.013$ ). However, chest drain losses were similar in both groups after 24 hours $(\mathrm{p}=0.17)$.

Conclusions: Normothermic high-flow $\mathrm{CPB}$ is associated with reduced transfusion requirements and chest drain losses when compared to hypothermic $\mathrm{CPB}$ in pediatric patients undergoing heart surgery.

\section{OP09 \\ Characterization of Plasma and Cell Surface CD163 in Pediatric Patients Undergoing Cardiopulmonary Bypass St. Louis J. \\ Children's Mercy Hospital, Kansas, USA}

Background/Purpose: Cardiopulmonary bypass (CPB) initiates an intense inflammatory response in children undergoing repair of congenital cardiac anomalies. CD163 is a monocyte scavenger receptor with the primary function of removing free hemoglobin from serum. Free hemoglobin catalyzes the formation of reactive oxygen species, worsening the inflammatory response and subsequent tissue injury. This study characterizes CD163 in patients undergoing CPB.

Methods: Twenty-seven patients with a congenital heart defect undergoing cardiopulmonary bypass were enrolled. All patients received intra-operative steroids. The average weight and age at the time of surgery was $11.3 \mathrm{~kg}$ (IQR: $7.1-16.5 \mathrm{~kg}$ ) and 31.8 months (IQR: 9.6-53.2 months), respectively. Blood samples were collected at four time points: prior to $\mathrm{CPB}$, upon removal from $\mathrm{CPB}$, following modified ultra-filtration (MUF), and 24 hours post-CPB. Monocyte CD163 receptor expression, soluble CD 163, IL10, IL6, IL8, TNF-alpha, free-plasma hemoglobin, and haptoglobin were assayed.

Results: All patients showed a significant increase in CD163 receptor expression at 24 hours post-bypass when compared to baseline (1567 vs. 10,800 MFI; p <0.0001). Soluble CD-163 increased significantly at the conclusion of MUF (278 vs. $439 \mathrm{ng} /$ $\mathrm{ml} ; \mathrm{p}<0.05)$, returning to pre-CPB levels at 24 hours. Freeplasma hemoglobin increased significantly at each time period, remaining elevated at $24 \mathrm{hrs}$ post-CPB. Other pro- and antiinflammatory cytokines expression followed a similar pattern to which is published in the literature.

Conclusion: CD-163 functions to bind hemoglobin moieties, thus reducing the injurious effects of reactive oxygen species. Increased expression of cell surface CD163 may be due to the administration of systemic steroids and the contact activation during CPB. The acute rise in soluble CD163 may result from the shedding of cell surface proteins during CBP or signaled by anti-inflammatory cytokines as IL10. CD163 may reduce the injurious effects of CPB in children.

\section{OP10 \\ Pediatric veno-arterial ECMO support: a twenty-year experience \\ Protopapas E.(1,2), Hakim N.(1,2), Zografos P.(1,2), Zavaropoulos P.(1,2), Alexopoulos C.(3), Sarris G. $(1,2)$ Athens Heart Surgery Institute, Athens, Greece(1), Department of Congenital Cardiac Surgery(2) and Pediatric Cardiac Intensive Care Unit, Iaso Children's Hospital, Athens, Greece(3)}

Background: Veno-arterial extracorporeal membrane oxygenation (VA-ECMO) is an established strategy for cardiopulmonary 
support, especially after pediatric cardiac operations. VA-ECMO support can be provided in three medically refractory circumstances: (1) cardiac failure (cardiac ECMO), (2) when cardiopulmonary resuscitation does not restore spontaneous circulation (ECPR), and (3) in respiratory failure (respiratory ECMO). This study aims to review our experience.

Methods: Between 1997 and 2017, our team used VA-ECMO in 48 patients in 3 hospitals. ECMO was used mainly for cardiac support after cardiac surgery $(n=43)$, instituted either intraoperatively $(\mathrm{n}=22)$ or in ICU $(\mathrm{n}=17)$, or, after catheter intervention $(\mathrm{n}=4)$. In 2 patients, ECMO indication was fulminant myocarditis, and respiratory failure in three. ECPR was used in 21 patients (4 in the catheter laboratory, 17 in ICU).

Results: Successful weaning from ECMO was achieved in 17 patients (35\%). Median duration of ECMO support was 137 hours (1hr-5 months). Survival from ECPR was 38\% $(\mathrm{n}=8)$ with median support duration 115 hours ( $1 \mathrm{hr}-5$ months), $(p=N S)$. Survival from intraoperative ECMO was $31 \%$, median support duration 108hrs, $(p=N S)$. Both myocarditis patients survived, while all 3 respiratory failure patients succumbed to infection. Prolonged support duration (over $137 \mathrm{~h}$ ) (but not age, body weight, or ECPR) was related to reduced weaning rate $(\mathrm{p}=0.01)$. Although median duration of support increased over last 9 years (2009-2017) from 117 hrs to 335 hrs, survival rate did not $(p=N S)$.

Conclusions: Despite low volume of VA-ECMO use (0-5 cases per year), partly reflecting our relatively high threshold for instituting this therapy, we have achieved increased duration of effective support over the last decade, with satisfactory overall weaning rate, including ECPR patients, who constituted almost half of our series.

\section{OP11 \\ Fontan Procedure without prior bidirectional cavopulmonary shunt (BCPS) \\ Hakim N.(1,2), Zografos P.(1,2), Protopapas E. (1,2), Zavaropoulos P.(1,2), Alexopoulos C.(3), Sarris G. $(1,2)$ Athens Heart Surgery Institute(1), Department of Congenital Cardiac Surgery (2) and Pediatric Cardiac Intensive Care Unit(3), Iaso Children's Hospital, Athens Greece}

Background: The Fontan palliation, introduced in 1968 to treat cardiac malformations unsuitable for biventricular repair, provides in series blood flow to the pulmonary and systemic circulation without the requirement for a right ventricular pumping chamber. Surgical results of the Fontan procedure have improved significantly over the years, with much benefit attributed to the staged approach to achievement of the Fontan circulation, a strategy which is now universally accepted. Nevertheless, in certain clinical situations such as late referral, staged Fontan may be either unnecessary or ill-advised. Therefore, we sought to analyze our experience with the non-staged (primary) Fontan operation.

Methods: The medical records of all 75 patients with anatomic or functional single ventricle who underwent a Fontan procedure between 1998 and 2017 by our team were retrospectively analyzed. Results: 58 patients (Group A) had undergone staged preparatory operation(s): (20 patients BT shunt, 11 PA banding, 1 Norwood stage). All patients had BCPS. 17 patients underwent the Fontan operation directly (Group B): 8 patients had a palliative operation (7 with prior BT shunt 1 with prior PA banding) and 9 patients without any prior staging procedure. 4 patients (3 Group A, 1 Group B) had a lateral tunnel procedure, and all others had an extracardiac Fontan. Median age was 5 years (range 1 to 29 years) for Group A and 7,5 years (range 3 to 28) for Group B. The overall deaths in Group A were 3: one early (hospital death) and 2 late deaths. There was one operative late death in Group B. On follow-up (median 9,6 years, range 0.4 to 16,5 years), all other patients remain in NYHA Class I. Cardiopulmonary exercise testing and MRI functional assessment did not reveal significant differences between the two Groups.

Conclusions: The Fontan operation can be performed primarily in selected patients without prior staging procedures with excellent early and late clinical outcome.

\section{OP12}

Use of 3D Printing in the evaluation of complex congenital heart disease (CHD): Report of initial experience

Protopapas E.(1,2), Zografos P.(1,2), Hakim N.(1,2), Bilalis L.(3), Zavaropoulos P.(1,2), Alexopoulos C.(4), Sarris G. (1,2)

Athens Heart Surgery Institute, Athens, Greece(1), Department of Congenital Cardiac Surgery, Iaso Children's Hospital(2), 3D-Life, Athens, Greece(3), Pediatric Cardiac Intensive Care Unit, Iaso Children's Hospital, Athens, Greece(4)

Background: In many subspecialties, the practice of modern medicine relies heavily on advanced imaging. Ultrasonography, Computerized Tomography and Magnetic Resonance Imaging can produce virtual 3D images aiming to provide physicians with improved appreciation of the anatomy. Three-dimensional printing (3D printing) of physical cardiac models is a new tool poised to help surgeons appreciate complex cardiac anatomic features and their interrelationships with surrounding tissues. We sought to explore the utility of creating anatomically accurate $3 \mathrm{D}$ printed models for patients with complex or unusual congenital heart defects in facilitating diagnostic understanding and surgical planning.

Methods: Based on contrast-enhanced computer tomography (CT) or magnetic resonance (MRI) images, after appropriate segmentation and processing, accurate $3 \mathrm{D}$ printed models of the relevant cardiac anatomy (including appropriately planned sections) were created. We present our initial experience.

Results: From June of 2014 until January of 2017, we designed and created accurate 3D printed cardiovascular models of sixteen (16) patients with anatomically challenging congenital heart defects, in order to facilitate clinical decision making. Issues explored included feasibility of biventricular repair in complex DORV $(n=3)$, approach to coronary anomalies (fistula $(\mathrm{n}=1)$, AAOCA $(\mathrm{n}=2)$ ), technical demands of complex aortic $(n=5)$ or pulmonary $(n=3)$ reoperations and PA-VSD-MAPCAS $(n=2)$. In all cases, precise appreciation of the underlying structural defect facilitated patient/ family education and, most importantly, performance of an optimal surgical operation.

Conclusions: Printing of 3D cardiac models is a new and very promising tool for the diagnostic assessment and preoperative preparations for patients with complex or unusual congenital heart defects. The opportunity to handle accurate physical models of the anatomy in ways impossible even at operation enables the care team to clarify aims and limitations of planned surgical interventions, appreciate potential procedural difficulties and avoid intraoperative surprises.

\section{OP13}

Late outcome with a focus on re-intervention and reoperation after arterial switch operation for transposition of the great arteries

Protopapas E.(1,2), Kornoukhov O.(5), Zografos P.(1,2), Hakim N. $(1,2)$, Samanidis G.(3), Zavaropoulos P.(1,2), Alexopoulos C.(4), Ilyin V.(5), Sarris G. $(1,2)$

Athens Heart Surgery Institute, Athens, Greece(1), Department of Congenital Cardiac Surgery, Iaso Children's Hospital, Athens, Greece

(2), $1^{\text {st }}$ Department of Cardiac Surgery, Onassis Cardiac Center, Athens, 
Greece(3), Pediatric Cardiac Intensive Care Unit, Iaso Children's Hospital, Athens, Greece(4), Filatov Children's Hospital, Moscow, Russia(5)

Background/Purpose: Although the Arterial Switch Operation (ASO) is long established as the procedure of choice for Transposition of the Great Arteries (TGA), investigation of the incidence and management of long-term complications is evolving. We aimed to review the collective experience of our two Centers with long-term outcome after ASO, focusing on late reinterventions / reoperations.

Methods: The records of 170 early survivors of the ASO for TGA performed by two remote Congenital Teams/Centers between January 1997 and December 2016 were reviewed. Median age and weight at ASO were 14 days (range, 3 days-3 years) and 3.5 (2.3511.8) $\mathrm{kg}$, respectively. Indications for ASO included TGA with intact ventricular septum (IVS) $(n=118)$, TGA with ventricular septal defect (VSD) $(\mathrm{n}=44)$, TGA-VSD-aortic coarctation $(\mathrm{n}=5)$, and TGA-LVOT obstruction $(\mathrm{n}=3)$. Median follow up was 5 (range 0.3-19) years.

Results: Late survival rate and freedom from reoperation at 20 years were $98.8 \%$ and $92.3 \%$, respectively. All surviving patients are in NYHA Class I. There were five catheter interventions $(n=5)$ and thirteen $(n=13)$ reoperations, of which two had been preceded by balloon dilation and/or stenting. Median time for reoperation after ASO was 6.5 (0.5-16) years. Indications were RVOT obstruction $(n=7)$, neo aortic valve stenosis $(n=1)$, aortic coarctation $(n=2)$, tricuspid regurgitation $(\mathrm{n}=1)$, left main bronchus compression $(\mathrm{n}=2)$, and none for coronary artery stenosis. Mortality for reintervention-reoperation was zero.

Conclusions: Late survival and functional outcomes of ASO were excellent. Reoperations-reinterventions are infrequent and most are performed within the first 10 years after ASO, with more than half involving RVOT or branch PA procedures.

\section{OP14}

Late correction of complete atrioventricular septal defect challenging but feasible in selective cases

Veit M.(1), Loup O.(1), Wustmann K.(2), Hutter D.(2),

Heinisch P. P.(1), Pfammatter J. P.(2), Schwerzmann M.(2),

Carrel T.(1), Kadner A.(1)

Department of Cardiovascular surgery, Center for Congenital Heart

Disease(1), Department of Cardiology, Center for Congenital Heart

Disease(2), Inselspital, Bern, Switzerland

Introduction: Therapy of choice of patients with complete atrioventricular septal defect (CAVSD) is surgical repair during early infancy. Survival without repair falls to $20 \%$ after two years of age, mainly because of pulmonary hypertension and cardiac failure. Experience with corrective surgery beyond the first year of life, is limited. We present our experience with correction of CAVSD in older children and adults.

Methods: Retrospective analysis of patients with CAVSD, who underwent corrective surgery beyond one year of age at our center. Results: Nine patients ( 3 male, mean age 23.1 years, range: $2-56$ years) were identified between 2009 and 2016. Five of the patients had trisomy 21. Follow up is complete (mean: 47.2 months). Prior to the operation, 8 patients had left atrioventricular valve (AV) regurgitation ( 3 mild, 4 moderate, 1 severe) and 8 right AV valve regurgitation (4 mild, 4 moderate). Moderate pulmonary hypertension (PHT) was found in 4 patients, severe PHT in 2. One patient presented in profound cardiac shock due to chordae ruptures. In one case, surgery was performed via anterolateral thoracotomy. Replacement of the left AV valve was necessary in 2 patients. Average time in the intensive care unit was 6.9 days, hospitalization time 22.9 days. Pacemaker implantation due to postoperative complete AV-block was necessary in 1 patient. 30 days mortality is $0 \%$. In long-term, one patient died due to severe thromboembolic complication of his mechanical mitral valve 51 months after repair. At last follow-up, all patients were in functional status NYHA I-II with normal left ventricular function. Residual left AV valve insufficiency is mild in 4, and moderate in 2 patients. Moderate PHT persists in 1 patient.

Conclusion: Late correction of CAVSD is challenging but feasible, and can provide good results. Careful preoperative evaluation and an interdisciplinary approach in a specialized center are mandatory for success.

\section{OP15}

Surgery in connective tissue disorders in pediatric age: a series of four cases

Cerejo R.(1), Silva M.(1), Rodrigues R.(1), Trigo C.(2), Fragata I.(3), Pinto F.(2), Fragata J.(1)

Cardiothoracic Surgery Department(1), Pediatric Cardiology Department (2) and Anesthesiology Department(3), Hospital De Santa Marta CHLC, EPE, Lisboa, Portugal

Introduction: Connective Tissue Disorders (CTD) such as Marfan (MFS), Loeys-Dietz (LDS) and other related syndromes are infrequent, with clinical manifestations becoming more evident with age. Cardiovascular malformations are life-threatening and, because of their aggressive nature, earlier surgical intervention is indicated. Although surgery in adults with CTD is well described, there is little data about surgery in children. We aim to describe the surgical experience in pediatric population with CTD in our Center.

Methods: In a recent period of 6 years (2011-2016), we identified four children with CTD that required a total of five surgical interventions. Clinical data of these patients were analyzed and a literature review about CTD and cardiovascular surgery in children was performed.

Results: In our series, the clinical diagnosis was: MFS (2), LDS (1) and Shprintzen-Goldberg syndrome (1). Median age at surgery was 17 years. Diagnosis were: aortic dissection in one (LDS), aortic aneurysm in two and aortic aneurysm with mitral regurgitation in one. Procedures were: David operation (2), David + hemiarch replacement (1), David + mitral valvuloplasty (1) and Thoracoabdominal aortic aneurysm repair (1). No mortality or significant complications were reported. Currently all patients remain asymptomatic. Reports on the surgical therapy in children with CTD are scarce, and case series have only a few dozen patients. Aortic surgery is the most common in this setting, with aortic valve-sparing root replacement the preferred technique. Reported mortality is $0-8 \%$ and long-term results are good. Because CTD complications are unusual in pediatric age, surgical indications, best procedures and operative results are difficult to establish.

Conclusions: Published series of CTD cardiovascular operations at a young age are small, and their safety, efficacy and long-term outcomes are unknown. Despite the high surgical complexity, they can be performed in children with low operative morbidity and mortality.

\section{OP16}

Adjustable FloWatch pulmonary artery banding for muscular VSD: palliative to curative operation Pelella G.(1), Gardner D.(2), Toolan C.(1), Ramaraj R.(2), Guerrero R.(1), Lotto A.(1), Dhannapuneni R.(1) 
Department of Congenital Cardiac Surgery(1) and Department of Paediatric Cardiology (2) Alder Hey Children's Hospital Trust, Liverpool, UK

Background: Pulmonary artery banding (PAB) leads to the spontaneous closure of muscular VSDs in some cases. In these patients, the $\mathrm{PAB}$ procedure may be curative rather than palliative. The FloWatch-PAB device is a remotely adjustable PA band. We report the curative de-banding experience in patients who underwent FloWatch-PAB implantation for multiple or muscular VSDs in our centre.

Methods: This is a retrospective study of patients who underwent FloWatch-PAB removal at Alder Hey Children's Hospital from January 2007 to January 2017. We excluded patients in whom the indication for pulmonary artery banding was other than multiple or muscular VSD. We included patients with associated lesions corrected at the time of the FloWatch insertion.

Results: Fifteen patients underwent FloWatch de-banding after a median time of 41 months (1.1-7.9 years). The indications for PAB were: muscular VSD (4) and multiple VSD (11). In 5/11 of the patients with multiple VSD, there was an association with a perimembranous VSD. Four patients underwent hypoplastic aortic arch repair concurrently with the PAB and 2 patients underwent coartation of the aorta repair prior to the insertion of the device. The median age at banding was 82 days (7-196 days). Four-fifteenths of patients $(26.6 \%)$ did not require cardiopulmonary bypass at de-banding, due to the complete closure of the VSD and absence of stenosis of the main pulmonary artery (MPA). Eight patients (53\%) did not require VSD closure; of these, 4 patients needed patch enlargement of the MPA. Perimembranous VSD closure and residual mid-muscular VSD closure was required in 5 and 2 patients respectively. Overall, $60 \%$ of our population required enlargement of the MPA.

Conclusions: FloWatch-PAB for muscular VSDs in the absence of perimembranous VSD can be considered as a curative operation. In some of these cases, removal of FloWatch and fibrous tissue is sufficient to restore pulmonary artery size and avoid CPB.

\section{OP17 \\ NHS staff benefit from international charity work as much as recipient hospital staff \\ Nichani S.(1), Nichani S.(2) \\ Barts and the London School of Medicine(1), East Midlands Congenital Heart Centre, Leicester, UK(2)}

Background: The burden of congenital heart disease disproportionately affects the developing world due to higher birth rates and a paucity of facilities. The developed world should play an active role in this huge problem by undertaking visits to the poorest countries to operate on children, as well as facilitating the creation of local expertise and capacity building.

Methods: We assessed the outcomes of 9 years of international charity activity by one charity, Healing Little Hearts (HLH), in terms of benefits to local recipient hospitals and patients as well as the benefits to the teams from the UK.

Results: Over the last 9 years, 5 countries have been visited and over 1000 operations performed. During each visit, an average of 12-15 children are operated on. In 2016, HLH undertook 21 charity trips by HLH during which 287 children were operated on. Each UK surgeon operated on a significantly higher number of children during the week than they would normally in the UK. Two-three trips per surgeon would add an additional 20-30\% operations each per year. The entire team's skills had to be adapted to working in less than ideal conditions in the host hospitals. Two centres in India were signed off as self-sufficient after capacity building.

Conclusions: UK teams benefit as much as the recipient populations and hospitals from charity trips abroad. Each cardiac unit in the UK should be encouraged to tie up with an appropriate hospital with potential. Nurses and doctors should be encouraged to go at an early stage in their careers. Recipient hospitals benefit hugely from training by visiting teams, but each hospital should be visited at least 3 times per year for a sustained effect. If data collection can be verified for accuracy then the operations could be added to the Central Cardiac Audit Database (CCAD).

\section{PP01}

Pulmonary valve replacement in patients under 16 years old with the background of a complete repair of Tetralogy of Fallot

Pavy C., Ghez O.

Royal Brompton Hospital, London, UK

Purpose: To study the fate of pulmonary valve replacements in patients under 16 years old who underwent a Tetralogy of Fallot repair.

Methods: This is a retrospective monocentric study from January 2000 to July 2017, where all patients under 16 years old who had a complete repair of Tetralogy of Fallot underwent a pulmonary valve replacement either by an aortic homograft (Ao group) or by a pulmonary homograft (PA group).

Results: A total of 37 patients were included, 21 in the Ao group and 16 in the PA group. The average age of Tetralogy of Fallot repair was 1 ( \pm 2.1 years). The PA group had its homograft implantation at an earlier age $(5 \pm 3.7$ years $)$ than the Ao group $(9.16 \pm 3.2$ years, $p=0.0019)$, with respectively smaller sizes (PA group: $19.9 \pm 2.9 \mathrm{~mm}$, Ao group: $21.2 \pm 2.8 \mathrm{~mm}$, $\mathrm{p}=0.0977)$. The average long-term follow-up was $8.3 \pm 4.4$ years, without any deaths. In total, there were $5(13 \%)$ reinterventions after pulmonary valve replacement, 2 (9.5\%) for homograft stenosis and one (4.7\%) for endocarditis in group Ao; compared with $2(11.7 \%)$ for homograft stenosis in the PA group. Among these re-interventions, there was one Hancock tube, 3 prosthetic biological valves replacements, and a Melody implantation. The mean lifespan of the pulmonary homograft was longer (9.6 \pm 0.7 years) than the aortic homograft $(6.2 \pm 3.1$ years) but not significantly $(p=0.0959)$. The shortest lifespan of the aortic homograft was 3 years compared with 9 years for the pulmonary homograft.

Conclusion: The homograft re-replacement operations rate remains low at 8 years for both pulmonary and aortic homografts with a longer longevity trend for pulmonary homografts.

\section{PP02}

Triple orifice left AV valve in A-V septal defect (AVSD) repair

Zografos P., Hakim N., Protopapas E., Alexopoulos C., Kyrvasilis G, Sarris $G$.

Athens Heart Surgery Institute, Iaso Children's Hospital, Athens, Greece

Background: The triple orifice left AV valve (LAVV), a rare anatomic malformation encountered during repair of partial or transitional AVSD, represents a challenge to surgical attempts to establish and/or preserve LAVV competence.

Methods: We present the case of an 18-month-old girl with the diagnosis of transitional A-V canal: There was a large primum and a small secundum ASD, three small VSD's under the bridging 
leaflets, and a dysplastic, moderately regurgitant LAVV, which was felt to be double orifice, based on preoperative echocardiography. There was major left to right shunt. At operation, a dysplastic LAVV with three orifices, a larger one anteriorly (through which the regurgitant flow passed) and two smaller posteriorly (with minimal regurgitation flow), was found. Satisfactory competence of the valve was achieved by partial closure of an atypical cleft from the large orifice to the septum. The smaller orifices were left untouched. All VSDs were closed with pledgeted sutures, and the ASD's were repaired with autologous pericardium.

Results: Intraoperative post repair TEE showed complete closure of all septal defects and excellent function of the LAVV with minimal regurgitation through each orifice, which remains well competent at 8 years of follow-up.

Conclusions: The triple orifice LAVV, encountered rarely during AVSD repair, can be repaired successfully, following individualized assessment and management of each orifice.

\section{PP03}

\section{Fontan Procedure: 10-year experience in a single} institution

Aung Y., Anzar S. Bu'Lock F., Mimic B., Speggiorin S., Corno A. F. East Midlands Congenital Heart Centre, Glenfield Hospital, Leicester, UK

Purpose: To evaluate outcomes over a 10-year period of Fontan procedures.

Methods: In 59 patients (pts) < 16years of age with extra-cardiac Fontan performed between 04/2005-03/2015, all clinical data, including demographics, history, hemodynamics, imaging, interventional/surgical procedures, follow-up with mortality and morbidities, were reviewed.

Results:

Pre-operative: Mean age at surgery was $5.2 \pm 1.9 \mathrm{yrs}(2.3-12.6)$, mean weight $17 \pm 5 \mathrm{~kg}(8-36)$. Dominant $\mathrm{LV}$ was present in $63 \%$ $(37 / 59), \mathrm{RV}$ in $37 \%(22 / 59)$.

Diagnosis: tricuspid atresia 14, DILV 11, PA with intact septum 7, cAVSD 7, DORV 7, HLHS 6, isomerism 5, cCTGA 2. Fifty-nine first-stage interventional/surgical procedures, 59 second-stage procedures (50/59 were bidirectional Glenn), and 9 third-stage procedures were performed before Fontan completion. Atrioventricular valve regurgitation was absent in $48 \%(28 / 59)$, mild in $44 \%(26 / 59)$, moderate in $8 \%(5 / 59)$. Mean oxygen saturation was $81 \pm 6 \%$ (65-93), mean hemoglobin $161 \pm 13 \mathrm{gm} / \mathrm{L}(130-186)$. Mean PA pressure $11 \pm 2 \mathrm{mmHg}$ (6-19), mean end-diastolic ventricular pressure $7 \pm 2 \mathrm{mmHg}$ (3-13). Two fifty-ninths (3\%) pts on ECMO underwent Fontan as salvage procedure.

Intra-operative: Conduit size: $15 \mathrm{~mm}$ in $1(1 \%), 16 \mathrm{~mm}$ in 12 $(20 \%), 18 \mathrm{~mm}$ in $40(69 \%), 20 \mathrm{~mm}$ in $6(10 \%)$, fenestrated in 56 $(95 \%)$ and non-fenestrated in $3(5 \%)$. Mean duration of $\mathrm{CPB}$ $140 \pm 68^{\prime}(62-420)$, mean aortic X-clamp $28 \pm 26^{\prime}(0-146)$, associated procedures in $28 \mathrm{pts}(47 \%)$.

Post-operative: Hospital mortality was 3\% (2/59), both with preoperative ECMO. Mean duration of mechanical ventilation $1.2 \pm 1.0$ day $(0-21)$; mean ICU and hospital stay respectively $3.5 \pm 4.0$ days (1-22) and $17 \pm 9$ days (7-51). Three patients $(5 \%)$ requiring post-operative ECMO all survived. Mean duration of chest drains $11 \pm 6$ days (4-33), mean chest drains losses $10.6 \pm 8.7 \mathrm{ml} / \mathrm{kg} /$ day $(1.5-20.3)$.

Post-operative complications: chylothorax in 15/55 (27\%), arrhythmias in 9/55 (16\%) all resolved pre-discharge, transient neurological complications in 5/55 (9\%), infection with positive cultures $4 / 55(7 \%)$, diaphragmatic paralysis $1 / 55$ (2\%). At mean follow-up $5.9 \pm 2.8$ years $(1.5-10.5)$ there was no late mortality, fenestration closure in 7/56 (12.5\%), protein-losing enteropathy in 3/56 (5.3\%)

Conclusions: a) up to 10-year follow-up showed good results, without late mortality; b) early outcomes were similar to literature reports, but with higher incidence of chylothorax and chest drain duration; c) these results prompted revision of standard postoperative protocols.

\section{PP04}

An 18-month-old child with complete atrioventricular block presenting initially as breath holding spells Hadas D.(1), Vida V. L.(2), Cerutti A.(3), Ferretto S.(1), Padalino M.(2), Reffo E.(3), Quinto L.(1), Milanesi O.(3), Leoni L.(1) Department of Cardiological Thoracic and Vascular Sciences(1), Paediatric and Congenital Cardiac Surgery Unit(2) and Department of Cardiac, Thoracic and Vascular Science(3), University of Padova, Padova, Italy, Paediatric Cardiology Unit, Department of Women's and Children's Health, University Hospital of Padova, Padova, Italy

Introduction: Breath holding spells are acknowledged to be common during the first years of life and are age-typical expressions of frustration or anger. They are characterized by the following sequence of symptoms: 1) a precipitating factor such as slight injury or emotional upset; 2) crying of short duration; 3) a respiratory gasp and breath holding in expiration; 4) cyanosis and/or pallor; 5) opisthotonic rigidity and loss of consciousness; and 6) flaccidity or convulsive movements. The so-called pallid BHS are precipitated by trauma rather than anger, and are known to be associated with cardiac asystole and EEG slowing. Long-term prognosis is generally excellent. The standard of care is reassurance for most patients, but children with severe sequel require further treatment. Eventually, some cases turn out to be not so benign. Prolonged asystole is known to occur in children with BHS. Unexpected death has been reported in children with BHS. Sudden deaths are thought to have been precipitated by primary breath-holding in at least two children. Severe ischemic encephalopathy has been reported as well. Some centers implant pacemakers in extreme asystolic BHS, presenting an improved quality of life. We describe the first case of complete atrioventricular block following asystole in BHS.

Case reports: An 18-month-old child with normal physiological and medical history, negative family history, normal pregnancy and perinatal development. First events were recorded during his early life with spontaneous resolution these events where interpreted as emotional spasm. From the age of 6 months, he suffered frequent episodes of loss of consciousness, up to many times a month, the majority of short duration, some lasting up to 30 seconds, but always with a spontaneous recovery and the parents report that the child often falls asleep after an event. In suspicion of breath holding spells, the child was treated with oral iron supplement.

During a visit to the paediatrician, an epileptic event was witnessed and he was referred for neurological investigations. EEG and video EEG performed appears compatible with transitional aspects cerebral hypoperfusion, with the transition to normal waking activities in 15-20 seconds, which is typical for breath holding spell Resting ECG was normal. Echocardiogram had no functional alterations.

Blood examination including a CBC, CRP and general biochemistry electrolyte levels and liver function tests came out normal. Microbiological tests were negative, and chest X-ray was normal.

He was then referred for a 4-day ECG Holter examination during episodes of crisis revealing sinus rhythm interruption by extreme bradicardya and junctional rhythm followed by sinus arrest which 
is followed by episodes of complete atrioventricular block with no spontaneous nodal or ventricular rhythm, while pauses reached about 20 seconds (Figure 1).

After a multi-disciplinary consultation and, in the light of the unusual event, we implanted a VVI epicardial abdominal pacemaker without complications. The pacemaker was programmed to minimum heart rate of 75 in accordance with the Holter examination done earlier that revealed a normal heart rate variability of 90-150. During the child's post surgical observation, an event of BHS was recorded, with normal sinus tachycardia followed by a sudden drop in heart rate and intervention of pacemaker with heart rate 75 for 20 seconds. There was no unconsciousness.

Comments: Breath-holding spells (BHS) are an involuntary, reflexic, nonepileptic paroxysmal disorder of infancy. Medical conditions to consider should include seizures, Chiari crisis, dysautonomia, cardiac arrhythmias, and central nervous system lesions. Here we present a first case of complete atrio-ventricular block mimicking the "assuming benign" asystolic pallid BHS, revealing the importance of an ECG-documented event in order to differentiate between the etiologies.

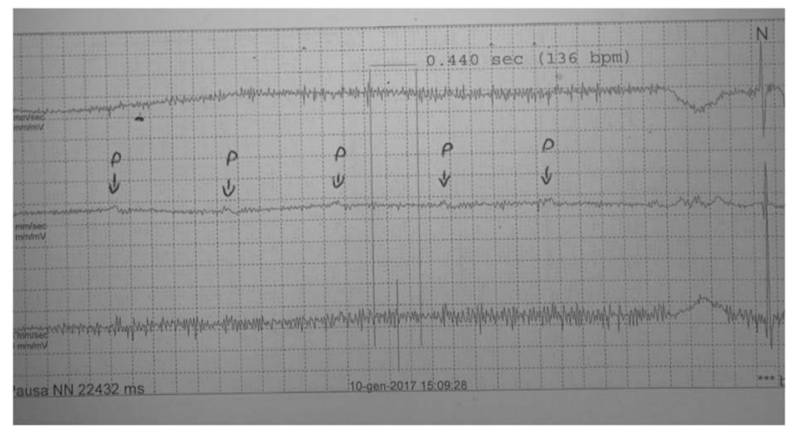

PP05

\section{Pediatric cardiac anaesthesia and intensive care in the} developing world

Cvetkovic M., Corno A. F.

East Midlands Congenital Heart Centre, University Hospitals of Leicester, Glenfield Hospital, Leicester, UK

Background: The opportunity to provide pediatric cardiac care in developing countries is at the same time is both a rewarding and frustrating experience. The challenges are numerous and unique and the benefits are intensely satisfying. Warning: It may be habit-forming. Challenges: The majority of populations in the developing world does not have access to safe anaesthesia and intensive care unit (ICU) services. The lack of adequate education is another area of great concerns. Primary challenges include selection of adequate patient population, equipment available, and provider needs. The maxim "Do no harm," applies.

- Patient population: One of the most difficult challenges is the patient selection. It is difficult to decline treatment to a child who could be treated in the developed world. The temptation to "do the most cases" should be resisted.

- Equipment: The equipment in most developing countries seldom reaches degree of technical sophistication. The presence of adequate ventilators, $\mathrm{ETCO}_{2}$ monitors, and invasive monitoring equipment is rare to nonexistent. Electrocardiographs, blood pressure cuffs, and pulse oxymetry are not standard equipment. In fact, more than $19 \%$ of operating rooms worldwide have no pulse oxymeter.
- Perioperative management: Perioperative management will vary considerably, according to the type of surgery, patient condition, status of equipment, and supplies available. In ICU, simple guidelines understood by local team are helpful.

- Provider needs: Healthcare providers should make certain that their routine immunizations are current. Specific information about the area can be obtained from the Centers for Disease Control and Prevention.

Conclusion: Considering the current state of national health services in underdeveloped countries, a lot of effort has to be made to make anaesthesia and ICU practice safer. Teaching makes a real difference in care, and newer educational technologies like telemedicine and simulation would help to further increase education and learning. Global priority should be given to reducing total perioperative-related mortality.

\section{PP06}

Successful repair of a neonatal mitral valve endocarditis Yong S.(1), Kudumula V.(1), Speggiorin S.(1)

East Midlands Congenital Heart Centre, Glenfield Hospital, Leicester, United Kingdom

Background/Purpose: Mitral valve endocarditis is a rare but, commonly fatal condition in the neonatal population. A literature search revealed only a handful of case reports. We aim to report a case of successful mitral valve repair during acute phase of infective endocarditis in a neonate.

Summary: A 16-day-old boy presented to local hospital with persistent pyrexia and right lower limb swelling. Blood cultures grew staphylococcus aureus. With septic arthritis in mind, he underwent surgical exploration of his right hip which was negative. $\mathrm{He}$ quickly deteriorated with increasing respiratory distress, bilateral pulmonary consolidation and an episode of pulmonary haemorrhage. He was stabilized in intensive care, requiring invasive ventilation and multiple inotropic support. An echocardiogram confirmed a large vegetation measuring $13 \mathrm{~mm}$ by $9 \mathrm{~mm}$ on the posterior mitral valve leaflet. He was taken to theatre the next morning. The vegetation was attached to the P2 segment of the mitral valve. This was excised in entirety, including the infective margins. This area was then repaired with a CardioCel bovine pericardial patch.

Post-operatively, he recovered very well. He was discharged after completion of six weeks of antibiotics. On serial follow ups, he has been noted to be clinically well and developing normally, with no complications. His mitral valve, to date, is functioning well with a mean gradient of $5 \mathrm{mmHg}$ and mild mitral regurgitation.

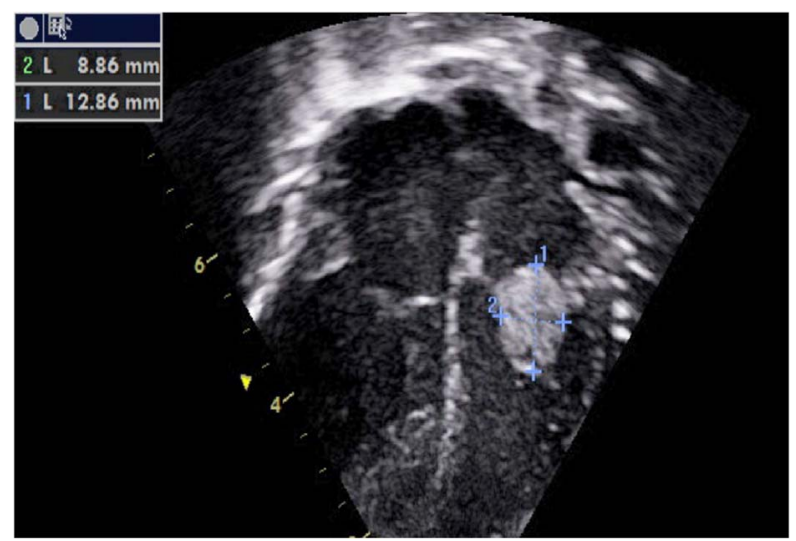




\section{PP07}

Decision making for an ex-premature infant with Trisomy 21 , severe chronic lung disease, ventricular septal defect with aortic override and patent arterial duct

Subrahmanyam Puthucode D., Linter K., Mimic B., Cvetkovic M., Corno A. F.

East Midlands Congenital Heart Centre University Hospitals of Leicester Glenfield Hospital Leicester, UK

Background: The decision-making when planning the timing and type of surgery becomes more challenging in presence of multiple co-morbidities.

Case summary: A 5-month-old infant, weighing $3.7 \mathrm{kgs}$, with Down syndrome, background of prematurity (32 weeks) and low birth weight $(1.2 \mathrm{kgs})$ was on anti-failure medications because of unrestrictive ventricular septal defect with overriding aorta and large patent arterial duct. Following multiple hospital admissions because of upper and lower airways infections requiring respiratory assistance, he was referred to our unit for further management. Chest X-ray and echocardiography confirmed the combination of uncompensated heart failure and acute and chronic lung disease. Decision making and risk assessment were facilitated by chest CT scan showing severe cystic lung disease with multiple areas of air trapping. The available options were: a) to continue high standard of aggressive intensive care, but accepting that he may not recover from the respiratory infection; b) the appealing surgical strategy of complete repair was judged very high risk on the basis of the CT scan; c) with anticipation of a difficult post-operative course, a staged surgical approach was decided.

Closure of patent arterial duct and staged pulmonary artery banding was undertaken. As expected, the post-operative period was complicated by several episodes of profound systemic desaturation and bradycardia. On the $9^{\text {th }}$ post-operative day, the patient was extubated and on $18^{\text {th }}$ post-operative day he was transferred in stable conditions to the referring hospital.

Conclusions:

a) There must be recognition of need to change management strategy.

b) All co-morbidities must be identified and thoroughly investigated, and in this case the information gathered from the CT scan was pivotal.

c) The alternative strategies can then be considered in an informed manner.

d) The decision made will continue to be reviewed as part of planning for the next steps in the management.

\section{PP08}

Single ventricle surgery in an infant with complex congenital cardiac anomalies, situs inversus and asplenia: A case report and literature review

Saraf F., BuLock F, Speggiorin S., Cvetkovic M.

East Midlands Congenital Heart Centre, University Hospitals of

Leicester, Glenfield Hospital, Leicester, UK

Background: Single ventricle surgery has undergone complex modification since its development in response to associated morbidity and mortality. At present, accounting for variations in techniques used, single ventricle surgery has successful outcomes. Case summary: An 8-month-old female infant, weighing $6.5 \mathrm{~kg}$, with complex congenital cardiac anomalies associated with situs inversus and asplenia. Antenatally diagnosed pulmonary atresia with confluent branch pulmonary arteries (PAs) supplied by tortuous patent ductus arteriosus (PDA), single ventricle with single outlet to aorta, right atrial isomerism with single atrioventricular (AV) connection, atrial-septal defect and single left-sided superior vena cava (SVC). In neonatal period, a $3.5 \mathrm{~mm}$ right modified Blalock-Taussig shunt (mBTS) and ligation of the PDA were performed. Bidirectional Glenn shunt (BDGS) was done under this admission. Flow was directed from the left SVC to the left PA. PAs were enlarged with homograft patch. Postoperatively, BDGS pressure was persistently raised to $27 \mathrm{mmHg}$. Cardiac contrast study revealed an area of torsion around the right PA outflow. A re-operation was performed with patch enlargement of right PA and BDGS. BDGS pressure remained 20-24 $\mathrm{mmHg}$. Echocardiography showed good venous return, laminar ventricular outflow and unobstructed aortic flow with moderate aortic valve regurgitation. Extubation was attempted on fourth postoperative day. On day six, suddenly desaturated requiring reintubation and inhaled nitric oxide. Pulmonary hypertension was suspected and sildenafil was commenced. Currently, she remains intubated with plan for CT angiography in a view of imaging BDGS and pulmonary vessels in preparation for trial of extubation. Conclusion: A mortality risk model to adjust for case mix in paediatric cardiac surgery patients revealed an $8.8 \%$ risk of 30 days mortality for this patient. The additional cardiac lesions or comorbidities were not taken into account. We managed to perform BDGS in this complex patient in a view of later Fontan repair with a good result at present.

\section{PP09}

Favorable results of tetralogy of Fallot repair with partial valve sparring transannular PA patching

Ilyin V., Karimov A., Kornoukhov Y.

Cardiac Surgery Department, Filatov Children's Hospital, Moscow, Russian Federation

Objectives: More than half of patients with TF have severe hypoplastic PA valve with thick and dysplastic leaflets that doesn't allow to use the full PV preservation technique of repair. We present our results of TF repair with partial valve sparring transannular patching (PVSTP) of the PA.

Methods: During 2008-2016, 97 patients with TF were operated on and in 24 of them the PVSTP technique was applied. After trans-PA valvar commissurotomy, the incision was extended via one of commissures onto the RV free wall to 1,1(range 0,7-1,5) $\mathrm{cm}$. A width of pericardial patch was calculated to establish normal PA diameter according patient's BSA. Median age at surgery was $0,8(0,3-2,3)$ years. Median preoperative PV Z-score was -3.4 (-0.6-6.5). Median follow-up time was $4.4(1-7,5)$ years. Reoperation was needed in one patient 5 months after repair because of residual subvalvar obstruction. The routine $2 \mathrm{D}$ echo was used in pre- and postoperative investigation.

Results: There was no operative and follow up mortality in this group. All patients are still asymptomatic, on sinus rhythm, doing well without any oral therapy. At 2D echocardiography, the RV function is good in all with median EF - $0,66(0,48-0,75)$, with the RV being not dilated in $96 \%$ of patients. The median peak gradient across the pulmonary outflow tract is 16 (6 to 55$) \mathrm{mm} \mathrm{Hg}$, the orifice of the PV being appropriate for the $\mathrm{BSA}$, giving a median Z-score of 1 ( -0.2 to +2.1$)$. Mild PV regurgitation is present in 16 patients, moderate in 8 and severe in none.

Conclusion: Tetralogy of Fallot repair with the PVSTP technique accompanies good clinical results and in most cases lets to avoid right ventricular dilation and dysfunction in a mid-term follow up. 
PP10

Surgical excision of cardiac tumors: 20 -year experience at a single institution

Pelella G., Guerrero R., Dhannapuneni R., Lotto A.

Alder Hey Children's Hospital, Liverpool, UK

Background/Hypothesis:

Cardiac tumors are rare with heterogeneous histology and location.

Indication for surgical resection is dictated by symptoms and position. The aim of the present study is to review our institution's results in patients who underwent resection of cardiac tumors since 1997.

Materials and methods:

Retrospective review from January 1997 to January 2017 was accomplished. We followed up on all patients including echocardiographic assessing regression or progression.

Results:

13 patients with a diagnosis of cardiac tumor were operated at our Institution in the study period. The demographic of the population and the histology subtype are described in Table 1.

Rhabdomyomas $(n=6)$ : Four of the six patients were operated in neonatal age, the remaining two at 2 and 3 months of age. In 4 of the 6 patients, the tumor was in the LVOT causing significant obstruction; while in two patients there was RVOT obstruction. Myxomas $(n=3)$ : Patients with this subtype were older. All the myxomas were excised from the left atrial septum repaired with a patch. One patient had associated mitral valve repair.

Pericardial Teratoma $(n=2)$ : One patient was operated in neonatal age, while the second was 10 months old. The new-born died for haemorrhagic complication while on ECMO support following patch enlargement of the ascending aorta after the resection of the pericardial teratoma.

Fibroma $(n=1)$ : one patient had a fibroma excised from the RV free wall at 8 months of age.

Haemangioma $(n=1)$ : one patient with right atrial haemangioma encasing the RCA was successfully operated and the coronary repaired.

The operation was carried out in neonatal period in 46\% (4 rabdomyoma due to LVOT obstruction, 1 haemangioma and 1 pericardial teratoma presented with respiratory distress).

We had one (7.6\%) in hospital death and no late death. At a mean follow up time of $77+/-67$ months no patient required reoperation and echocardiogram excluded regrowth.

Conclusions:

Surgical excision can be performed with low mortality and morbidity even when patients are operated in the neonatal age. We showed good long term follow up with no tumor regrowth.

\section{VP01}

Cone reconstruction of tricuspid valve in patient with Ebstein anomaly: a surgical video presentation

Protopapas E.(1,2), Hakim N.(1,2), Zografos P. (1,2), Zavaropoulos P. (1,2), Alexopoulos C.(3), Aggelopoulos N.(4), Sarris G. $(1,2)$ Athens Heart Surgery Institute, Athens, Greece(1), Department of Congenital Cardiac Surgery (2) and Pediatric Cardiac Intensive Care Unit (3), Iaso Children's Hospital, Athens, Greece, Department of Cardiology, Iaso General Hospital, Athens, Greece(4)

Background: Ebstein Disease (ED) is a rare congenital cardiac malformation accounting for $1 \%$ of congenital heart disease (CHD). It is a myopathy of the right ventricle characterized by failure of tricuspid valve delamination, resulting in extremely variable valve morphology and dysfunction. Clinical presentation varies widely and depends on anatomic severity. Surgical techniques for treatment of Ebstein Disease have included both tricuspid valve replacement and a great variety of reparative techniques. The Cone reconstruction, introduced by Da Silva in 2004, involves complete mobilization of tricuspid valve tissue used to achieve reconstruction of a conical valve in the true tricuspid annulus, achieving competence by valve-to-valve tissue apposition. We demonstrate the Cone technique in the attached video.

Case Report Summary Description: A symptomatic (NYHA class II) 24-year-old woman with severe Ebstein's malformation of the tricuspid valve (type C), and moderate to severe tricuspid insufficiency underwent cone reconstruction. The functional annulus was displaced apically with a large atrialized right ventricular $(\mathrm{aRV})$ part, which was plicated longitudinally after the $360^{\circ}$ complete mobilization of the deformed tricuspid valve. The leaflets were joined to create a cone of valve tissue, which was subsequently re-attached to the true tricuspid annulus. The repair was stabilized with a prosthetic tricuspid ring $38 \mathrm{~mm}$. Post-operative tricuspid valve and cardiac function overall was excellent and recovery was uneventful. At 6-month follow-up, she is free of symptoms, and echo shows trivial tricuspid regurgitation and reduced $\mathrm{RV}$ volume.

\section{VP02}

Construction of a monocusp with porcine extracellular matrix (CorMatrix ${ }^{\circledR}$ ) by means of PV anterior leaflet extension during tetralogy of Fallot repair

Pelella G.(1), Speggiorin S.(2), Dhannapuneni R.(1), Guerrero R.(1), Lotto A.(1)

Alder Hey Children's Hospital Trust - Congenital Cardiothoracic

Department , Liverpool Merseyside, United Kingdom(1), East Midlands Congenital Heart Centre, Glenfield Hospital, Leicester,

United Kingdom(2)

Background: To describe a technique of constructing monocusp leaflet extension during tetralogy of Fallot repair, using porcine extracellular matrix CorMatrix ${ }^{\circledR}$ patch.

Description: We employ this technique in patients in whom a transannular patch is needed and the pulmonary valve (PV) anatomy presents an anterior leaflet. After the VSD closure and right ventricle outflow tract obstruction (RVOTO) resection accomplished, an incision over the main PA in performed and extended into the RVOT across the PV annulus. The anterior leaflet is therefore divided into two hemi-leaflets and a partial commissurotomy is performed to increase mobility. A patch of CorMatrix is cut oversized over a dilator bigger than the predicted PV for body surface area and shaped to extend the anterior leaflet so that it will coapt with the posterior leaflets in diastole. The leaflet extension patch is sutured on both free edges of the hemi-leaflet to reach their respective commissures at the junction with the infundibulum where the suture line is then continued over the free edge of the previously incised RVOT. A second patch of CorMatrix is then shaped as a classical transannular patch, making it redundant enough to accommodate the monocusp in systole. This technique has the advantages over previously described techniques to allow for increased extended leaflet mobility; therefore improving valve competency. It also has the advantage of using patch materials with unique regenerating properties, with the potential to grow.

\section{VP03}

Pulmonary valve replacement in adult congenital cardiac surgery using St Jude Trifecta valve

Pelella G.(1), O’Dea E.(2) Speggiorin S.(2), Dhannapuneni R.(1), Guerrero R.(1), Lotto A.(1) 
Congenital Cardiothoracic Department, Alder Hey Children's Hospital Trust, Liverpool, UK(1), East Midlands Congenital Heart Centre Glenfield Hospital, Leicester, UK(2)

Background: Pulmonary valve regurgitation is common after tetralogy of Fallot repair when a transannular patch is employed. Long term consequences are right ventricular (RV) dilation and dysfunction with variable degree of tricuspid valve insufficiency. In this video, we demonstrate how we replace the pulmonary valve in adult patients with severe pulmonary valve regurgitation. Description: All patients undergo preoperative workup with cardiac MRI to calculate biventricular volumes and to ascertain the presence of residual shunt especially at ventricular level. After general

Table 1.

\begin{tabular}{|c|c|c|c|c|c|c|c|}
\hline & $\mathbf{n}$ & $\begin{array}{l}\text { Gender } \\
M, F\end{array}$ & $\begin{array}{l}\text { Median } \\
\text { Age } \\
\text { (Range) }\end{array}$ & $\begin{array}{l}\text { Median } \\
\text { Weight } \\
\text { (Range) }\end{array}$ & Position & Symptoms & $\begin{array}{l}\text { Antenatal } \\
\text { Diagnosis } \\
(\mathbf{Y}, \mathbf{N})\end{array}$ \\
\hline \multirow[t]{2}{*}{ Rhabdomyoma } & 6 & 0,6 & $\begin{array}{l}\text { 11d } \\
\quad(3 \mathrm{~d}-82 \mathrm{~d})\end{array}$ & $\begin{array}{l}3 \mathrm{Kg} \\
\quad(2.4-4.6)\end{array}$ & $\begin{array}{l}\text { 4 LVOT } \\
\text { (RV + IVS) }\end{array}$ & $\begin{array}{l}3 \text { no Symptoms } \\
3 \text { part of Tuberous } \\
\text { sclerosis }\end{array}$ & 2,4 \\
\hline & & & & & $\begin{array}{l}1 \mathrm{RVOT} \\
1 \mathrm{RVOT} \\
\text { and IVS }\end{array}$ & & \\
\hline \multirow[t]{2}{*}{ Mixoma } & 3 & 2,1 & $\begin{array}{l}4.5 \mathrm{yrs} \\
(46- \\
138 \mathrm{~m})\end{array}$ & $\begin{array}{l}21 \mathrm{Kg} \\
(19-25)\end{array}$ & $2 \mathrm{LA}+\mathrm{IAS}$ & $\begin{array}{l}2 \text { no Symptoms } \\
1 \text { Carney complex }\end{array}$ & 0,3 \\
\hline & & & & & $1 \mathrm{LA}$ & & \\
\hline \multirow[t]{2}{*}{ Teratoma } & 2 & 1,1 & $\begin{array}{l}5 \mathrm{~m} \\
\quad(3 \mathrm{~d}-10 \mathrm{~m})\end{array}$ & $\begin{array}{l}5.25 \mathrm{Kg} \\
(2.4-8.1)\end{array}$ & 1 pericardium & $\begin{array}{l}\text { 1,cought and } \\
\text { cardiomegaly }\end{array}$ & 0,2 \\
\hline & & & & & $\begin{array}{l}1 \text { pericardium/ } \\
\text { Ao. Root }\end{array}$ & 1 , hydrops fetalis & \\
\hline Fibroma & 1 & 1,0 & $6 \mathrm{~m}$ & $6.38 \mathrm{Kg}$ & $1 \mathrm{RV}$ free wall & 1 no symptoms & 0,1 \\
\hline Haemangioma & 1 & 1,0 & $27 \mathrm{~d}$ & $3.7 \mathrm{Kg}$ & $1 \mathrm{RA}$ & 1 arrhythmias & 1,0 \\
\hline TOTAL & 13 & 5,8 & 1.8 Months & $4 \mathrm{Kg}$ & & $\begin{array}{l}7 \text { Symptoms vs } \\
6 \text { no } \\
\text { symptoms }\end{array}$ & 3,10 \\
\hline
\end{tabular}

LVOT $=$ left ventricle outflow tract; RVOT $=$ right ventricle outflow tract; IVS $=$ interventricular septum $\mathrm{LA}=$ left atrium; $\mathrm{RV}=$ right ventricle; $\mathrm{RA}=$ right atrium;

$\mathrm{Ao}=$ aortic; $\mathrm{d}=$ days; $\mathrm{m}=$ months; yrs $=$ years

anaesthesia, a perioperative TOE with bubble study under Valsalva manoeuvre is performed to exclude intra-cardiac shunt at atrial level not previously detected. Before the redo sternotomy is performed, CPB circuit is set up to allow both standard intrathoracic cannulation and femoro-femoral cannulation, in case of accidental cardiac re-entry injury.

Cardiac dissection is performed and, if no intracardiac shunts are presents, the procedure is conducted on cardiopulmonary bypass (CPB) on a beating heart. Otherwise aortic cross clamping and cardioplegic arrest is used. The RV outflow tract is dissected and the transannular patch excised. The appropriate prosthetic valve size is anchored to the infundibulum for about $2 / 3$ of the ring circumference with 2 hemi continuous polypropylene sutures. Care is taken to position the valve with 2 struts lying anteriorly, to prevent leaflets malfunctioning. Bovine pericardium patch is used to reconstruct the RVOT across the prosthetic valve ring to which it is attached to create an unobstructed pathway to the prosthetic valve orifice without oversizing the patch so to reduce the RVOT.

In case of an extremely dilated RV, the prosthetic valve can be sutured completely to the RVOT muscle, reducing significantly the infundibular volume, as the bovine pericardium patch is used only to reconstruct the main pulmonary artery.

In case of aneurysmatic RVOT, a longitudinal infundibular plication is employed to reduce the RVOT volume.

\section{VP04}

Right Cervical cannulation for VA-ECMO support

Pelella G.(1), Cunningham K.(2), Harvey C.(3), Lotto A.(1),

Peek G.(4)

Congenital Cardiothoracic Department. Alder Hey Children's Hospital Trust, Liverpool, UK(1), Liverpool Womens Hospital, Liverpool, UK (2), ECMO Unit, University Hospitals of Leicester Glenfield Hospital NHS Trust, Leicester, UK(3), Division Pediatric Cardiothoracic Surgery, Montefiore Health System Kings College Hospital School of Medicine, Bronx, New York, USA(4)

Background: In this video, we show how we cannulate for Veno-Arterial ECMO support (VA ECMO) through cervical cannulation using the right internal jugular vein (RIJV) and right common carotid artery (RCCA). This site is chosen in preference to the femoral approach as it avoids associated complications, particularly amongst newborns and non-walking infants.

Moreover, cervical cannulation can be performed at the bed space, in an emergency setting, during cardiac massage.

Description: The vascular access involves a transverse incision on the right side of the neck, at the level of the second cervical crest, following skin creases. After skin incision for about 2 to $3 \mathrm{~cm}$, division the platysma muscle is accomplished to reach the sternocleidomastoid muscle which is retracted laterally while the omohyoid muscle is retracted medially. The RIJV and the RCCA are dissected freely and encircled with silk ties proximally and distally. After systemic heparinization ( $75 \mathrm{u} / \mathrm{kg}$ of IV heparin), the carotid artery is cannulated first: the distal silk is tied to ligate the artery while a vascular clamp controls the proximal end of the vessel. A transverse incision is made and an arterial ECMO cannula is inserted into the vessel to a depth of 2 to $3 \mathrm{~cm}$ to reach the aortic arch. The arterial cannula is fixed by the proximal silk tie around the artery, below the incision. The distal silk previously tied is knotted around the cannula to further secure the cannula.

The same process is used for venous cannulation. The venous wall is more fragile than the artery and can be easily damaged during the procedure. The venous cannula is inserted $6-7 \mathrm{~cm}$ inside at the level of the vein incision to reach the RA.

Both cannulas were fixed to the skin using heavy sutures.

The neck incision is now closed using interrupted sutures in 5-0 polypropylene. 